\title{
Effects of Socioeconomic Status on Anthropometry and Food Consumption in 35-45 Year Old Women
}

\author{
Riddhi Shah $^{1}$, Rupali Sengupta ${ }^{2}$ \\ ${ }^{1}$ Student (MSc CND-2), Department of Clinical Nutrition and Dietetics, Dr. BMN College of Home Science, NAAC-Re-Accredited "A+ \\ "Grade with CGPA 3.69/4 (Autonomous), 338, R.A. Kidwai Road, Matunga (E), Mumbai: 400019, Maharashtra, India. \\ 172riddhi@gmail.com \\ ${ }^{2}$ Head of the Department, D2partment of Clinical Nutrition and Dietetics, Dr. BMN College of Home Science, NAAC-Re-Accredited \\ "A+" Grade with CGPA 3.69/4 (Autonomous), 338, R.A. Kidwai Road, Matunga (E), Mumbai: 400019, Maharashtra, India
}

\begin{abstract}
The female gender plays an important role in a family, managing children and other family members. In this course, the health of the women is adjusted to a large extend. Socioeconomic status plays an important role in maintaining a healthy lifestyle. Socio economic status (SES) could indicate a difference in dietary diversity in individuals The following study was conducted to know the nutritional status of the women in Mumbai. The purpose of the study was to assess the consumption of different food groups among the higher socio-economic status and lower economic status sample. The study was conducted to find the correlation between the food consumption and anthropometric measurements. Consumption of the various food groups by different socio-economic status was noted using the semi quantitative Food Frequency Questionnaire. Due to the prevalence of COVID-19 lockdown, the string method was used (Ashwell, 2010), which indicated the preponderance of abdominal obesity in women. Socioeconomic status was calculated using BMC classification which included Ration Card details, Annual Income detail. Results showed that low socioeconomic status women did not focus much on healthy eating habit, and were found to have less abdominal fats ( $p=0.002)$. Prevalence of high calorie food consumption was found in higher socioeconomic status. $(p=0.001)$. Imbalance of food group consumption was observed between different SES and quality of food consumption was compromised. It can be concluded that healthy food options should be made available at lower rates for lower SES, making changes in government policies can help to achieve a balance in nutrition among different SES.
\end{abstract}

Keywords: Women, Socio economic status, dietary pattern, Anthropometry

\section{Introduction}

Female gender plays an important role in a family and experiences a lot of stress. In a study it was found that women have higher levels of stress as compared to men, particularly stress about money was observed by the author Wheeles et al. 2001. In year 2009, Mbada et al., conducted a systematic research showing a negative association between SES and BMI in Nigeria (i.e. a developing country). Different categories of SES were considered for the study. It was concluded that the trend for being overweight and obesity, was noted in developed countries, and it was also observed in developing countries too. This change might be due shift from traditional diets to western diets and reduced levels of physical exercise. In addition, a rapid increase in the level of sedentary jobs had a major role in the development of the current epidemic of being overweight or obesity. (Khan et al., 2014).

World Health Organization (WHO) defines overweight and obesity as abnormal or excessive fat accumulation that presents a risk to health. A simple measure commonly used to classify overweight and obesity in adults is body mass index (BMI). BMI is defined as a person's weight in kilograms divided by the square of his height in meters $(\mathrm{kg} / \mathrm{m} 2)$. WHO identifies overweight when BMI is greater than or equal to 25; and obesity when BMI is greater or equal to 30. In Asians, the cut-offs for overweight $(\geq 23.0 \mathrm{~kg} / \mathrm{m} 2)$ and obesity $(\geq 25.0 \mathrm{~kg} / \mathrm{m} 2)$ are lower than WHO criteria due to risk factors and morbidities. (WHO, 2020)

A cross-sectional study from the Florey Adelaide Female Aging Study determined that the increase in percent FM- fat mass was mostly due to reduced lean mass. The increase in abdominal percent FM was due to more FM deposited in the abdominal region. The study showed the impact of aging on resting metabolic rate (RMR) and macronutrient oxidation rates as a potential cause for the observed body composition changes during aging. Result showed that changes in body composition was due to alterations in energy balance, with a positive energy balance leading to weight gain and a negative balance resulting in weight loss. It concluded that body composition change was associated with aging. It occurred in the absence of weight fluctuation. It was also found that changes in RMR during aging may be due to changes in body composition. (Flier et al., 2004)

\section{Aim}

To study the effect of socio economic status on anthropometry measurements and food consumption for women aged $35-45$ years

\subsection{Objectives}


- To assess the consumption of different food groups among the higher socio economic status and lower economic status sample.

- To evaluate the anthropometric measurements of the samples..

- To identify the food groups that is majorly consumed by different socio economic status samples

- To find the correlation between the food consumption and anthropometric measurements amongst the sample.

\section{Material and Methodology}

Target group selection:

Women from selected wards and falling under different socio-economic groups were selected by random, stratified random. (35-45 years age group). Subjects are selected from lower socioeconomic status and higher socioeconomic status group.

\section{Socioeconomic status}

SES was estimated in Kuppuswami classification which considering indicators like material possessions, highest education, highest occupation, and type of house. The modified Kuppuswami classification is based on occupation, education, and income which were modified in 2010. Type of schooling was one of the important indices used by Indian authors where school fees, medium of education, and type of school (public or private) were factored in the composite SES indicator.

Table 1: Kuppuswami 2010 classification

\begin{tabular}{|l|c|c|c|c|c|}
\hline $\begin{array}{l}\text { Education of head of } \\
\text { family }\end{array}$ & Score & $\begin{array}{c}\text { Occupation of head of } \\
\text { family }\end{array}$ & Score & $\begin{array}{c}\text { Total per capita } \\
\text { family income per } \\
\text { month (as given }\end{array}$ & Score \\
\hline Professional degree & 7 & Professional & 10 & 2000 and above & 12 \\
\hline Graduate & 6 & Semi profession & 6 & RS 1000-1999 & 10 \\
\hline Intermediate/diploma & 5 & Clerical/shop/farm & 5 & RS 750-999 & 6 \\
\hline High school & 4 & Skilled worker & 4 & RS 500-749 & 4 \\
\hline Middle school & 3 & Semiskilled worker & 3 & $300-499$ & 3 \\
\hline Primary school & 2 & Unskilled worker & 2 & RS 101-299 & 2 \\
\hline Illiterate & 1 & Unemployed & 1 & Less than RS 100 & 1 \\
\hline
\end{tabular}

questionnaire

\section{Dietary pattern}

A food frequency questionnaire was designed to obtain information on overall dietary quality rather than nutrient composition and intake. The food frequency examined how often samples eats certain foods, and the size of the portions. This method is quick and inexpensive but under-reporting is common. Food item list were divided into 5 major that included cereals, pulses, dairy products, fruits and vegetables (IFCT 2020). Snacking food item consumption frequency was asked.

\section{Anthropometric measurements}

WtHR that is waist to height ratio was measured to indicate higher risk of obesity-related cardiovascular diseases; it is correlated with abdominal obesity. As due to nationwide lockdown, Dr Margaret Ashwell 2010 view was been circulated among the samples which said start by cutting a piece of string to the length of your height. The next step was to fold the piece of string in half and wrap it around your middle. If the two ends of the string struggle to meet, your visceral fat level is too high

\subsection{Method of Preparation}

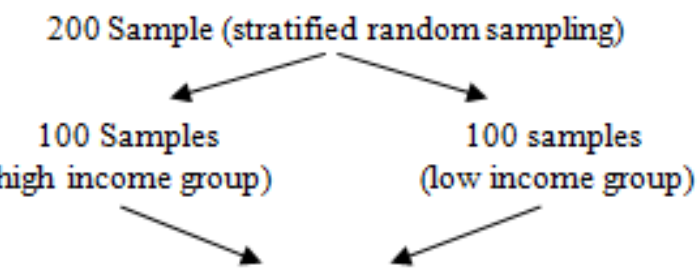

Food frequency questionnaire

(semi-quantitative food groups)

and

Anthropometric Measurements

(String Method)

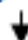

Nutrition education program (NEP)

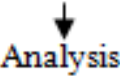

Result and discussion

Conclusion

\section{Results and Discussion}

\subsection{Medical condition}

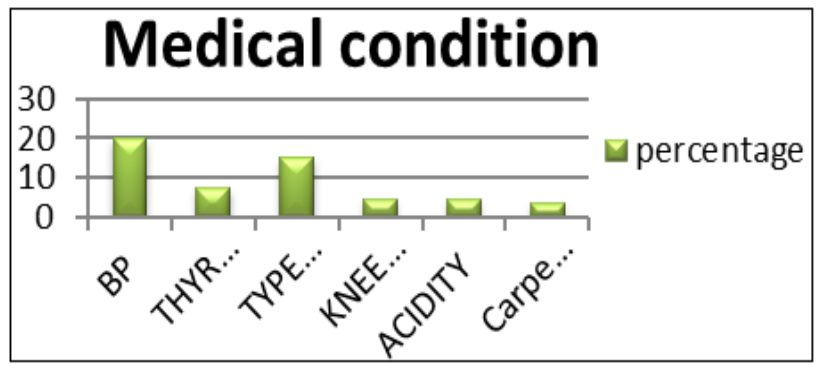

Grape 4.1: Medical condition

Lifestyle diseases are non-communicable diseases. They are caused by lack of physical activity, unhealthy eating, alcohol, substance use disorders and smoking tobacco, which can lead to heart disease, stroke, obesity, type II diabetes and many more conditions. Maximum number of the women (20\%) suffered from hypertension, $15.4 \%$ of the women suffered from diabetes mellitus. Thyroid, knee pain, was also found prevalent among the age group of 35 to 45 years. Starting with daily exercise regime can help to reduce weight and thus can help to reverse many lifestyle related disorders.

\subsection{Anthropometric measurements (String method)}

Table 4.2: Sting Method

\begin{tabular}{|c|c|c|c|c|c|}
\hline String method & $\mathrm{N}$ & Mean & $\mathrm{Df}$ & F-value & Significant \\
\hline Less than 0.5 & 11 & $27.00 \pm 5.21$ & 2 & 2.844 & .063 \\
\hline Exact 0.5 & 20 & $29.45 \pm 6.85$ & & & \\
\hline
\end{tabular}




\begin{tabular}{|c|c|c|l|l|l|}
\hline More than 0.5 & 73 & $26.54 \pm 44.08$ & & & \\
\hline Total & 104 & $27.15 \pm 44.91$ & & & \\
\hline
\end{tabular}

Dr. Margaret Ashwell in 2010 said start by cutting a piece of string to the length of your height. The next step is to fold the piece of string in half and wrap it around your middle. If the two ends of the string struggle to meet, your visceral fat level is too high. Due to prevalence of COVID 19 pandemic lockdown, string method was utilized to know t how much abdominal (belly) fat women have. Measuring height with a piece of string, and then folding the length of string that matches height in half and check to see if it fits around waist.
It was observed that most of the women were obese that is most of the women measured more than 0.5 parameter. 20 subjects had measurements exact 0.5 , which stated that the women had no excess amount of visceral fats

Very less subjects were in the category of underweight. 11 subjects measured the less than 0.5 and were under the category of underweight.

\subsection{Comparison between food group and SES}

Table 4.3: Comparison between food group and SES

\begin{tabular}{|c|c|c|c|c|c|c|c|}
\hline & & $\mathrm{N}$ & Mean & $\mathrm{DF}$ & Mean Square & $\mathrm{df}$ & Sig. \\
\hline \multirow{4}{*}{ Cereal } & LSES & 26 & $43.92 \pm 11.97$ & 2 & 773.173 & 7.808 & 0.001 \\
\hline & MSES & 34 & $50.58 \pm 11.44$ & 101 & 99.028 & & \\
\hline & HSES & 44 & $41.77 \pm 6.97$. & 103 & & & \\
\hline & Total & 104 & $45.19 \pm 10.58$ & & & & \\
\hline \multirow{4}{*}{ Pulse } & LSES & 26 & $36.30 \pm 10.75$ & 2 & 337.242 & 3.402 & 0.037 \\
\hline & MSES & 34 & $41.88 \pm 10.59$ & 101 & 99.128 & & \\
\hline & HSES & 44 & $36.54 \pm 8.90$ & 103 & & & \\
\hline & Total & 104 & $38.23 \pm 10.18$ & & & & \\
\hline \multirow{4}{*}{ Milk } & LSES & 26 & $19.50 \pm 6.94$ & 2 & 822.945 & 15.961 & 0 \\
\hline & MSES & 34 & $28.44 \pm 8.04$ & 101 & 51.56 & & \\
\hline & HSES & 44 & $20.27 \pm .6 .58$ & 103 & & & \\
\hline & Total & 104 & $22.75 \pm 8.15$ & & & & \\
\hline \multirow{4}{*}{ Vegetables } & LSES & 26 & $57.76 \pm 11.89$ & 2 & 539.806 & 3.609 & 0.031 \\
\hline & MSES & 34 & $65.64 \pm 15.69$ & 101 & 149.564 & & \\
\hline & HSES & 44 & $59.68 \pm 7.42$ & 103 & & & \\
\hline & Total & 104 & $61.15 \pm 12.53$ & & & & \\
\hline \multirow{4}{*}{ Fruits } & LSES & 26 & $32.38 \pm 16.01$ & 2 & 1128.276 & 6.451 & 0.002 \\
\hline & MSES & 34 & $33.11 \pm 12.13$ & 101 & 174.905 & & \\
\hline & HSES & 44 & $43.77 \pm 12.19$ & 103 & & & \\
\hline & Total & 104 & $36.48 \pm 13.90$ & & & & \\
\hline \multirow{4}{*}{ Beverages } & LSES & 26 & $15.76 \pm 4.90$ & 2 & 309.123 & 7.298 & 0.001 \\
\hline & MSES & 34 & $18.76 \pm 8.19$ & 101 & 42.36 & & \\
\hline & HSES & 44 & $13.09 \pm 5.77$ & 103 & & & \\
\hline & Total & 104 & $15.61 \pm 6.89$ & & & & \\
\hline \multirow{4}{*}{ Bakery } & LSES & 26 & $19.92 \pm 8.91$ & 2 & 137.322 & 2.492 & 0.088 \\
\hline & MSES & 34 & $15.76 \pm 7.30$ & 101 & 55.104 & & \\
\hline & HSES & 44 & $16.68 \pm 6.65$ & 103 & & & \\
\hline & Total & 104 & $17.19 \pm 7.52$ & & & & \\
\hline \multirow{4}{*}{ Snacks } & LSES & 26 & $36.00 \pm 19.49$ & 2 & 1543.245 & 7.502 & 0.001 \\
\hline & MSES & 34 & $21.77 \pm 15.18$ & 101 & 205.7 & & \\
\hline & HSES & 44 & $22.68 \pm 9.22$ & 103 & & & \\
\hline & Total & 104 & $26.69 \pm 15.22$ & & & & \\
\hline
\end{tabular}

Above table 4.3 states the relationship between the socioeconomic status and consumption of various food products such as cereals, pulses, milk and milk products, fruits, vegetables, beverages, bakery, snack items. It was observed that consumption of cereals was higher among the middle socio economic status women than higher and lower socio economic status.

Middle socio economic status were found to consuming high amount of pulses with mean value of $41.88 \pm 10.59$ which is highest compared to other socioeconomic strata. However the data did not show any significant difference when compared to other socioeconomic status. Study conducted by Kumar et al., showed similar results about the consumption of cereals. Considering the milk and milk product consumption, similar trend was observed with milk and milk product consumption. MSES consumed milk and milk product on higher level with mean value of $28.44 \pm 8.0$ as compared with higher and lower socio economic status. While comparing the data it was observed that the value for milk consumption was non-significant.

Consumption of vegetables was noted to be higher in MSES as compared to other socio economic status that is higher SES and lower SES. NFHS-4 found that consumption of food items, such as pumpkin, carrots, squash, dark green leafy vegetables, liver, heart, other organ meat, fish, shellfish, legumes and nuts, and flesh food, was significantly associated with maternal education but not with household wealth. 
Fruits are generally available at higher rate in the market. The study conducted showed that higher socio economic status had higher consumption of the fruits by the mean value of $43.77 \pm 12.19$ and after comparing the fruit consumption in different socio economic status, however the $\mathrm{p}$ value is less than 0.005 when the consumption of the fruits was studied among the different SES. The findings are in line with reports, confirming that family socioeconomic status and the affluence of the place of residence are both important factors in terms of fruit and vegetables intake. The (PURE) study analyzed the frequency of fruit and vegetables consumption among adults in 18 countries (including Poland) and found that the lowest intake was observed in low-income countries (2.14 serving/day), while the highest in high-income countries (5.42 serving/day)

To know the beverage consumption among the women, various intake of beverages consumption was asked to different socio economic status group people. It was noted that the consumption of beverages was high among the middle class women. A significant difference was observed among the women.

\subsection{Supplement Consumption}

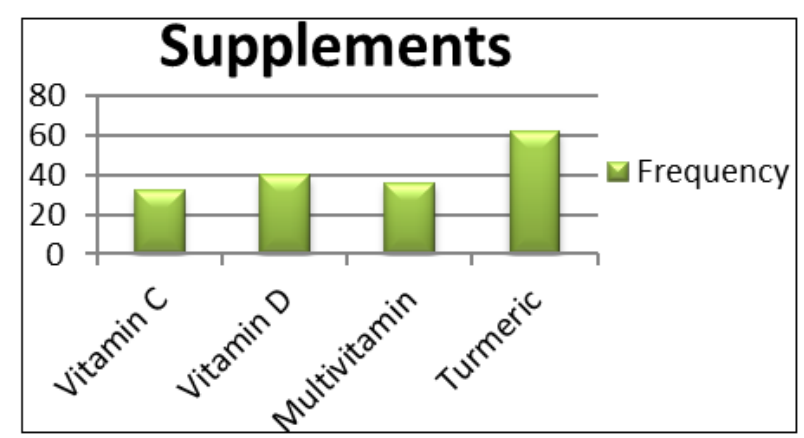

Figure 4.3: Supplement consumption

As the study was conducted during the lockdown period of COVID-19. Consumption of various immune supplements has observed. It was observed that $59.6 \%$ of the subject consumed ready home available turmeric spices- Turmeric has antiviral and anti-bacterial properties. Turmeric is also rich in vitamin $\mathrm{C}$, vitamin $\mathrm{B} 6$, and other antioxidants. $39 \%$ of the subjects consumed vitamin D supplements, while $30 \%$ consumed vitamin C supplements to boost immunity. Report by ASSOCHAM shows spice exports from India have gone up by 23 per cent in June 2020, compared in the same month 2019 year. Which indicates increased consumption of spice throughout the world.

\subsection{Junk food consumption}

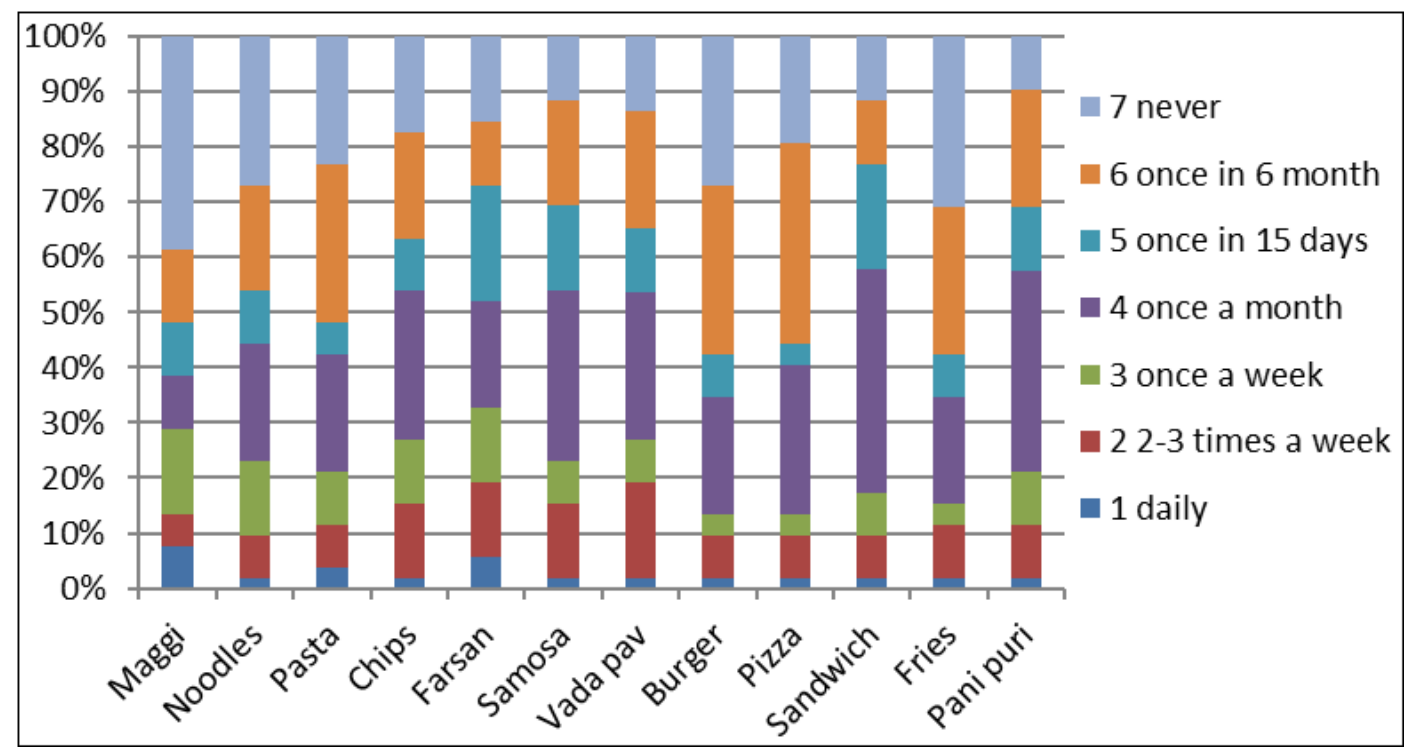

Table 4.5

Junk food are foods and drinks low in nutrients (e.g. vitamins, minerals and fibre) and high in kilojoules, saturated fat, added sugar and/or added salt. Eating too much junk food is linked to serious health problems. It was observed that junk food such as pizza, burger, sandwich, samosa, Vada pav, noodles was mostly consumed once a month by the subjects. It was noted that these junk food was not prepared at home, it was mostly purchased from the street vendors and restaurants.

Easy availability of junk food at lower prize and appealing to taste buds are the reasons that lead to increase in consumption of junk food. Cost is a massive component of the draw to junk food. It tends to be extremely cheap. Sahana in 2011, says that, "junk food costs three times less as much to have a healthful diet as it does to eat junk food and fast-food products. When junk food is so accessible, affordable and convenient, it becomes easy to forgo nutritious food. The high sodium and sugar content may lead to unto wards consequences, but they make these foods appealing to the taste buds."

The findings of NFHS-4 (around 10\% of women consume fried foods daily and $36 \%$ weekly. Aerated drinks are consumed daily by $5 \%$ of women and weekly by $20 \%$ of women. 
Table 4.6: Food group and Anthropometry

\begin{tabular}{|c|c|c|c|c|c|c|}
\hline & & $\mathrm{N}$ & Mean & $\mathrm{df}$ & $\mathrm{F}$ & Sig. \\
\hline \multirow{4}{*}{ Cereal } & Underweight & 19 & $40.73 \pm 9.56$ & 2 & 0.294 & 0.746 \\
\hline & normal & 12 & $43.00 \pm 6.61$ & 101 & & \\
\hline & Obese & 73 & $45.41 \pm 11.59$ & 103 & & \\
\hline & Total & 104 & $45.19 \pm 15.50$ & & & \\
\hline \multirow{4}{*}{ Pulse } & Underweight & 19 & $35.73 \pm 9.20$ & 2 & 3.446 & 0.036 \\
\hline & normal & 12 & $32.58 \pm 6.57$ & 101 & & \\
\hline & Obese & 73 & $39.80 \pm 0.54$ & 103 & & \\
\hline & Total & 104 & $38.23 \pm 0.18$ & & & \\
\hline \multirow{4}{*}{ Milk } & Underweight & 19 & $23.36 \pm 6.07$ & 2 & 0.734 & 0.482 \\
\hline & normal & 12 & $20.08 \pm 8.14$ & 101 & & \\
\hline & Obese & 73 & $23.02 \pm 8.62$ & 103 & & \\
\hline & Total & 104 & $22.75 \pm 8.15$ & & & \\
\hline \multirow{4}{*}{ Vegetables } & Underweight & 19 & $60.81 \pm 9.74$ & 2 & 0.862 & 0.426 \\
\hline & normal & 12 & $56.83 \pm 11.63$ & 101 & & \\
\hline & Obese & 73 & $61.94 \pm 13.28$ & 103 & & \\
\hline & Total & 104 & $61.15 \pm 2.53$ & & & \\
\hline \multirow{4}{*}{ Fruits } & Underweight & 19 & $35.63 \pm 13.10$ & 2 & 4.66 & 0.002 \\
\hline & normal & 12 & $25.75 \pm 10.12$ & 101 & & \\
\hline & Obese & 73 & $38.46 \pm 13.95$ & 103 & & \\
\hline & Total & 104 & $36.48 \pm 3.90$ & & & \\
\hline \multirow{4}{*}{ Beverages } & Underweight & 19 & $13.52 \pm 4.92$ & 2 & 2.976 & 0.055 \\
\hline & normal & 12 & $12.58 \pm 3.42$ & 101 & & \\
\hline & Obese & 73 & $16.65 \pm 7.50$ & 103 & & \\
\hline & Total & 104 & $15.61 \pm 6.89$ & & & \\
\hline \multirow{4}{*}{ Bakery } & Underweight & 19 & $17.42 \pm 7.93$ & 2 & 1.909 & 0.153 \\
\hline & normal & 12 & $13.25 \pm 5.73$ & 101 & & \\
\hline & Obese & 73 & $17.78 \pm 7.52$ & 103 & & \\
\hline & Total & 104 & $17.19 \pm 7.52$ & & & \\
\hline \multirow{4}{*}{ Snacks } & Underweight & 19 & $29.00 \pm 17.05$ & 2 & 0.465 & 0.629 \\
\hline & normal & 12 & $23.58 \pm 9.13$ & 101 & & \\
\hline & Obese & 73 & 26.6015 .58 & 103 & & \\
\hline & Total & 104 & $26.63 \pm 5.20$ & & & \\
\hline
\end{tabular}

Table 4.10: Food group and Anthropometry

In the above given table 4.10 comparison of consumption of various food items was made with the different BMI category.

A significant relation was observed between the consumption of the cereals and BMI (body mass index). It was observed that mean value of $45.41 \pm 11.59$ was found in obese group consuming cereal which was highest when compared to the other BMI categories. Consumption of pulses was found to be higher in the obese people with mean of $39.80 \pm 10.54$, no significance was observes between the BMI category after comparison.

Milk and milk product did not show any significant difference with the level of obesity. While comparing the data it was observed that underweight and obese women consumed milk and milk products with same mean of 23.36 \pm 6.07 . p values was not significant.

With different fruits and vegetables comparison was made. It was found that obese women consumed more of fruits and vegetables compared to other class of BMI category. Fruit consumption had $\mathrm{p}$ value equal to 0.002 , which is considered to be significant.

High amount of beverages consumption was observed in the obese women. $16.6575 \pm 7.50$ mean of obese women consumed beverages such as tea, coffee, milkshakes, soft drinks etc. high beverage consumptions indicates high calorie intake in the diet. Controlling the portion size of beverages in a day can help to reduce the amount of kilo calorie intake.

Unhealthy snacking pattern was observed among the underweight women. Consumption of the vada pav, samosa was observed to be higher among the underweight women.

Thus it can state that control the food item intake in the daily diet might help the women to maintain the BMI to the normal range.

Due to over consumption of various food groups there is increase in an amount of calorie consumption. With increase in the calorie intake there is direct increase in amount of fats in the body. Hence leading to obesity among the subject.

Thus it can be stated that controlling the amount of the food intake, calorie intake, might help the responses in maintaining a negative energy balance in the body. Can help to reduce the excess amount of the weight. Maintaining normal BMI can help to stay away from many noncommunicable disorders

\section{Conclusion}


The study findings gave the importance of dietary, lifestyle, and socioeconomic determinants of obesity which were highlight mainly in adult women population living in Mumbai.. Taking the high risk approach, culturallyappropriate, community-based interventions should be initiated to help increase nutrition awareness among women of low education and socioeconomic levels. Understanding the importance of a healthy balanced diet and physical activity in the prevention of lifestyle-related diseases, regardless of genetic susceptibility, is crucial. Nutrition awareness campaigns are indeed recommended; however, strategies to improve the environments within which individual behavioral decisions are made, should be considered, mainly those related to food availability, cost of healthy foods, and access to physical activity opportunities. Most important is the delivery of a stable food security level for all the households in the six Governorates of Lebanon. Lifestyle factors are policy-relevant elements and hence, policy makers and commissioners of health services who are responsible for public health should tailor their efforts and resources to tackling obesity in light of its dynamics in the adult population.

\section{References}

[1] Alkerwi, Vernier, Sauvageot. (2015). Demographic and socioeconomic disparity in nutrition of a novel Correlated Component Regression approach. British Medical Association Journal, 2014-006814

[2] Baird, Weinberg, Zhou, Kamel, mcconnaughey, Kesner. (1999). Preimplantation urinary hormone profiles and the probability of conception in healthy women. Fertile Journal, 71:40-4

[3] Bray, R. M., Camlin, C. S., Fairbank, J. A., Dunteman, G. H., \& Wheeless, S. C. (2001). The Effects of Stress on Job Functioning of Military Men and Women. Armed Forces \& Society, 27(3), 397-417

[4] Cadagan, D., Khan, R., \& Amer, S. (2014). Female adipocyte androgen synthesis and the effects of insulin. Molecular genetics and metabolism reports, 1, 254-263

[5] Chirumbolo, Salvatore. (2020). Oxidative Stress, Nutrition and Cancer: Friends or Foes. The World Journal of Men's Health. 38. 10.5534/wjmh.190167

[6] Chen YP. (2016). Acupuncture for hot flashes in women with breast cancer: A systematic review. Journal of Cancer Research and Therapeutics; 12:535

[7] Darlene E. Berryman, Edward O. List, Lucila Sackmann-Sala, Ellen Lubbers, Rachel Munn, John J. Kopchick. (2011). Growth hormone and adipose tissue: Beyond the adipocyte. Growth Hormone \& IGF Research, 21, 3,113-123

[8] Deborah Leachman Slawson, Nurgul Fitzgerald, Kathleen T. Morgan. (2013). Position of the Academy of Nutrition and Dietetics: The Role of Nutrition in Health Promotion and Chronic Disease Prevention. Journal of the Academy of Nutrition and Dietetics, 2013.05.005, 113, 7, (972-979)

[9] De Novaes Soares C, Almeida OP, Joffe H, Cohen LS. (2001). Efficacy of Estradiol for the Treatment of Depressive Disorders in Perimenopausal Women: A
Double-blind, Randomized, Placebo-Controlled Trial. Arch Gen Psychiatry. 58(6):529-534

[10] Dora Il'yasova, Peter Scarbrough, Ivan Spasojevic. (2012). Urinary biomarkers of oxidative status, 413, 19-20, 1446-1453

[11] Dunson DB, Baird DD, Wilcox AJ, Weinberg CR. (1999). Day-specific probabilities of clinical pregnancy based on two studies with imperfect measures of ovulation. Hum Reprod;14:1835-1839

[12] E. Pamuk. (1998). Socioeconomic Status and Health Chartbook: Health , United States, Hyattsville, Md.: National Center for Health Statistics

[13] Ford ES, Ajani UA, Croft JB, Critchley JA, Labarthe DR, Kottke TE, Giles WH, Capewell S. (2007). Explaining the decrease in U.S. deaths from coronary disease, 1980-2000. N Engl J Med.; 356: 2388-2398

[14] Fotenos AF, Mintun MA, Snyder AZ, Morris JC, Buckner RL. (2008). Brain Volume Decline in Aging: Evidence for a Relation Between Socioeconomic Status, Preclinical Obese Condition, and Reserve. Arch Neurol. 65(1):113-120

[15] Freeman EW, Sammel MD, Lin H, Nelson DB. (2006). Associations of Hormones and Menopausal Status with Depressed Mood in Women With No History of Depression. Arch Gen Psychiatry ;63(4):375-382.

[16] Friedman, H. S., Tucker, J. S., Schwartz, J. E., Tomlinson-Keasey, C., Martin, L. R., Wingard, D. L., \& Criqui, M. H. (1995). Psychosocial and behavioral predictors of longevity: The aging and death of the "Termites." American Psychologist, 50(2), 69-78

[17] Georgina E; Hughes, Claude L.; Burger, Henry G; Robertson, David Fraser, Ian S. (2009). Atypical estradiol secretion and ovulation patterns caused by luteal out-of-phase (LOOP) events underlying irregular ovulatory menstrual cycles in the menopausal transition, Menopause, 16 - 1

[18] Ghaben, A.L., Scherer, P.E. (2019). Adipogenesis and metabolic health. Nat Rev Mol Cell Biol 20, 242-258

[19] Głąbska, D.; Guzek, D.; Groele, B.; Gutkowska, K. (2020). Fruit and Vegetable Intake and Mental Health in Adults: A Systematic Review. Nutrients, 12, 115.

[20] H L Barlett, S M Puhl, J L Hodgson, E R Buskirk, (1991). Fat-free mass in relation to stature: ratios of fat-free mass to height in children, adults, and elderly subjects, The American Journal of Clinical Nutrition, 53, 51112-1116

[21] Joan Shaver, Elizabeth Giblin, Martha Lentz, Kathryn Lee. (2018). Sleep Patterns and Stability in Perimenopausal Women. Sleep, 116, 556-561

[22] Kern PA, Ranganathan S, Li C, Wood L, Ranganathan G (2001). "Adipose tissue tumor necrosis factor and interleukin-6 expression in human obesity and insulin resistance". American Journal of Physiology. Endocrinology and Metabolism. 280 (5): E745-51.

[23] Kershaw EE, Flier JS (2004). "Adipose tissue as an endocrine organ". The Journal of Clinical Endocrinology and Metabolism. 89 (6): 254856. Doi:10.1210/jc.2004-0395.

[24] Kevin R. Short, Janet L. Vittone, Maureen L. Bigelow, David N. Proctor, and K. Sreekumaran Nair. (2004). Age and aerobic exercise training effects on whole body and muscle protein metabolism American 
Journal of Physiology-Endocrinology and Metabolism 286:1, E92-E101

[25] Lewer, D., Meier, P., Beard, E. (2016 . Unravelling the alcohol harm paradox: a population-based study of social gradients across very heavy drinking thresholds. BMC Public Health 16, 599

[26] Lichiro Shimomura, Robert E. Hammer, James A. Richardson, Shinji Ikemoto, Yuriy Bashmakov. (2016). Insulin resistance and diabetes mellitus in transgenic mice expressing nuclear SREBP-1c in adipose tissue: model for congenital generalized lipodystrophy, 10. 12: 3182-3194

[27] Lobo RA. (2019). Menopause and care of the mature woman. In: Comprehensive Gynecology. 7th ed. Philadelphia, Pa.: Elsevier; 2017.

[28] Marie E. Thoma, Mary L. Hediger, Rajeshwari Sundaram, Joseph B. Stanford, C. Matthew Peterson, Mary S. Croughan, Zhen Chen, and Germaine M. Buck Louis. (2012). on behalf of the ENDO Study Working Group Journal of Women's Health 21:10, 1074-1081

[29] Michael W O'Reilly, Punith Kempegowda, Mark Walsh, Angela E Taylor, Konstantinos N Manolopoulos, J William Allwood, Robert K Semple, Daniel Hebenstreit, Warwick B Dunn, Jeremy W Tomlinson, Wiebke Arlt. (2017). AKR1C3-Mediated Adipose Androgen Generation Drives Lipotoxicity in Women With Polycystic Ovary Syndrome, The Journal of Clinical Endocrinology \& Metabolism, 102, 9,3327-333

[30] N Santoro, J R Brown, T Adel, J H Skurnick. (1996). Characterization of reproductive hormonal dynamics in the perimenopause., The Journal of Clinical Endocrinology \& Metabolism, 41495-1501

[31] Njelekela, M.A., Mpembeni, R., Muhihi, A. (2009). Gender-related differences in the prevalence of cardiovascular disease risk factors and their correlates in urban Tanzania. BMC Cardiovasc Disord, 9, 30

[32] Osamu Hashimoto, Masayuki Funaba, Kazunari Sekiyama, Satoru Doi, Daichi Shindo, Ryo Satoh, Hiroshi Itoi, Hiroaki Oiwa, Masahiro Morita, Chisato Suzuki, Makoto Sugiyama, Norio Yamakawa, Hitomi Takada, Shigenobu Matsumura, Kazuo Inoue, Seiichi Oyadomari, Hiromu Sugino, Akira Kurisaki, (2018). "Activin E Controls Energy Homeostasis in Both Brown and White Adipose Tissues as a Hepatokine", Cell Reports, 25, 5, 1193-1203

[33] Parraga, I. M. (2017). Determinants of food consumption. Journal of the American Dietetic Association, 90, 661-3

[34] Sai Krupa Das, Edward Saltzman, Megan A. Mccrory, L. K. George Hsu, Scott A. Shikora, Gregory Dolnikowski, Joseph J. Kehayias, Susan B. Roberts. (2004). Energy Expenditure Is Very High in Extremely Obese Women, The Journal of Nutrition, 134, 6, 14121416

[35] Sarah de Ferranti, Dariush Mozaffarian (2008). The Perfect Storm: Obesity, Adipocyte Dysfunction, and Metabolic Consequences, Clinical Chemistry, 54, 6, 1, 945-955

[36] Toomey, Clodagh M.; Cremona, Alexandra; Hughes, Katie; Norton, Catherine; (2015). A Review of Body
Composition Measurement in the Assessment of Health, 30, 1, 16-32(17)

[37] Turnbull, A., Karapanagiotidis, T., Wang, H. (2020). Reductions in task positive neural systems occur with the passage of time and are associated with changes in ongoing thought. Sci Rep 10, 9912

[38] Van Beek, Van Klinken, J.B., Pronk, A.C.M. (2015).. The limited storage capacity of gonadal adipose tissue directs the development of metabolic disorders in male C57B1/6J mice. Diabetologia 58, 1601-1609

[39] Wilcox AJ, Weinberg CR, Wehmann RE, Armstrong EG, Canfield RE, Nisula BC. (1985). Measuring early pregnancy loss: laboratory and field methods. Fertil Steril;44:366-374.

[40] Williams, D. (2010). Socioeconomic Differentials in Health: A Review and Redirection. Social Psychology Quarterly, 53(2), 81-99.

[41] Wirth, Alfred; Wabitsch, Martin; Hauner, Hans (2014). "The Prevention and Treatment of Obesity". Deutsches Ärzteblatt International. 111 (42): 705-713.

[42] Yongmei Liu, Jingzhong Ding, Trudy L. Bush, J. Craig Longenecker, F. Javier Nieto, Sherita Hill Golden, Moyses Szklo. (2001). Relative Androgen Excess and Increased Cardiovascular Risk after Menopause: A Hypothesized Relation, American Journal of Epidemiology, 154, 6489-494

[43] Killgore, W. D. S., Cotting, D. I., Thomas, J. L., Cox, A. L., McGurk, D., Vo, A. H., et al. (2008). Postcombat invincibility: Violent combat experiences are associated with increased risk-taking propensity following deployment. Journal of Psychiatric Research, 42(13), 1112-1121

[44] Monson, C. M., Fredman, S. J., \& Adair, K. C. (2008). Cognitive-behavioral conjoint therapy for posttraumatic stress disorder: Application to operation enduring and Iraqi freedom veterans. Journal of Clinical Psychology, 64, 958-971

[45] Jakupcak, M., Luterek, J., Hunt, S., Conybeare, D., \& McFall, M. (2008). Post-traumatic stress and its relationship to physical health functioning in a sample of Iraq and Afghanistan war veterans seeking postdeployment VA health care. Journal of Nervous and Mental Disease, 196, 425-428.

\section{Author Profile}

Riddhi Shah, is a Student of MSc CND-2 Department of Clinical Nutrition and Dietetics in Dr. BMN College of Home Science, NAAC-Re-Accredited "A" Grade with CGPA 3.64/4 (Autonomous), 338, R.A. Kidwai Road, Matunga (E), Mumbai: 400019, Maharashtra, India 